\title{
Environmental Will, Environmental Behavior and Knowledge Sharing - an Empirical Study Based on Resource-Based Enterprises
}

\author{
Shijin Wang, Guirong Ji*, Huiying Zhou \\ School of Business, Jiangsu Normal University, Xuzhou Jiangsu Province, China, 221116
}

Received: 20 December 2020

Accepted: 3 May 2021

\begin{abstract}
Resource-based enterprises, as an important part of China's macro-economy and an important guarantee for the operation of the national economy, have brought serious environmental pollution problems as well as great economic benefits. Under the background of the new era of ecological priority in China, the analysis of the environmental behavior choice of resource-based enterprises as micro-subjects is of guiding significance to the construction of environmental governance system in China. Based on the results of 503 questionnaires of resource-based enterprises, this paper combs the internal mechanism of corporate reputation, leader awareness, technical support and market profits influencing corporate environmental behavior, introduces corporate environmental will as mediating variable, knowledge sharing and corporate social responsibility as regulating variable, constructs a theoretical model of corporate environmental behavior drivers. The hypothesis is put forward and tested by Structural Equation Model and Hierarchical Regression Analysis. The results show that: corporate reputation, leader awareness, technical support and market profits all have significant positive effects on corporate environmental will; At the same time, corporate environmental will plays a full intermediary role in the process of corporate reputation and leader awareness influencing the corporate environmental behavior, and has part of the intermediary role in the process of technical support and market profits influencing corporate environmental behavior. Knowledge sharing plays a moderating role in the process of transforming leader awareness into corporate environmental behavior. When the level of knowledge sharing is higher, it has a strong regulatory effect on the transformation of leader awareness to the corporate environmental will.
\end{abstract}

Keywords: corporate environmental will, corporate environmental behavior, knowledge sharing, resource enterprises, Planning Behavior Theory

*e-mail: 13605203093@163.com 


\section{Introduction}

Although achievements have been made in the construction of the environmental governance system currently being implemented in China, as the first subject of environmental pollution, the environmental will and environmental behavior of enterprises have affected the process of environmental governance system construction. And to solve the conflict between economic and environmental benefits more and more important. The Fourth Plenary Session of the $19^{\text {th }}$ Central Committee of the Communist Party of China pointed out that it is necessary to strictly enforce the ecological environmental protection responsibility system, strengthen the management of binding indicators such as environmental protection, natural resource control, energy conservation and emission reduction, and strictly implement the responsibility of enterprises and government supervision. However, in reality, many companies passively implement environmental behaviors and rush to save energy and reduce emissions in order to achieve the environmental governance goals set by the government, it is contrary to the original intention of energy saving and emission reduction. In order to more effectively promote the construction of environmental governance systems, improving the will of enterprises to implement environmental behaviors has become a major breakthrough direction in the future. In this context, the implementation of corporate environmental behavior has become an objective requirement for economic and social development.

As an important part of our national economy, resource-based enterprises have caused tremendous damage to resources and the environment while creating economic benefits. The investment in the treatment of industrial pollution sources nationwide in 2017 was 68.55 billion yuan, of which 7.64 billion yuan was used to treat wastewater, 44.63 billion yuan to treat waste gas, and 1.27 billion yuan to treat solid waste. The proportion of enterprises in industrial pollutant emissions cannot be ignored. At present, resourcebased enterprises are in a critical period of green transformation. However, due to their strong resource dependence, low added value of products, and high cost of technological innovation, enterprises will save transformation costs as much as possible out of rational considerations, and therefore the subjective will to implement environmental behaviors is not strong. And traditional government environmental regulations focus on end-of-pipe governance, which lacks guidance for companies' prior environmental behavior [1]. In fact, as a micro-decision-making subject, the implementation of environmental behavior can't be simply regarded as a passive compliance under government regulation, and its internal green culture and knowledge sharing are more important. Among resource-based companies, $84.5 \%$ of the surveyed companies included environmental protection into their corporate target system, $70.3 \%$ of companies regularly carried out employee environmental protection skills training and environmental protection knowledge sharing, and $69.4 \%$ of employees actively practiced corporate green activities, showing that most resource-based enterprises begin to pay attention to environmental culture and environmental protection concept, but there are still a small number of enterprises that lack internal green knowledge promotion and sharing. Therefore, how to promote knowledge sharing and enhance the environmental will of enterprises is an important problem in the selection of environmental behavior of resource-based enterprises. Studying the mechanism of corporate environmental behavior is of great significance to the improvement of the environmental governance system proposed in the report of my country's 19th National Congress. At the same time, the study of multiple factors affecting enterprise environmental behavior and its mechanism of action should also be the focus of the study. Only by clarifying the driving factors of enterprise environmental behavior, can we formulate the corresponding strategies to promote the implementation of enterprise green behavior.

Corporate environmental behavior, also known as "corporate pro-environmental behavior" , "corporate green behavior" and "corporate cleaner production behavior". Domestic and foreign scholars define the environmental behavior of enterprises slightly different. For example, environmental behaviors specifically refer to behaviors that are environmentally friendly to reduce environmental hazards [2]. Corporate environmental behavior refers to a series of strategies involving the relationship between corporate business operations and the environment, or corresponding to external pressures, and proactive measures aimed at reducing environmental hazards [3]. According to the definition of the above research and the availability of enterprise research data, this paper defines the environmental behavior of enterprises as the behavior of enterprises to integrate the ideas of environmental protection and resource saving into business activities under the pressure of government, market and society, and to carry out a series of green management activities and green technological innovation. Corporate environmental behavior is the result of the interaction between external factors and internal characteristics. Based on the perspectives of institutional, organizational and resource perspectives, scholars discuss the influence mechanism of enterprise environmental behavior from three aspects: environmental regulation, stakeholders, and corporate characteristics. As far as environmental regulation is concerned, the results of some documents show that environmental regulation has a certain direct effect on the environmental behavior of enterprises [4,5], but most scholars believe that a single environmental policy is not directly causal [6], related to the transmission mechanism [7], the strictness of policy implementation [8]. As for stakeholders, with the increase of environmental pollution and public awareness of environmental protection, China's 
environmental policy has changed from direct government control to direct control and indirect control, consumers [9, 10], investment Stakeholders [11], communities [12, 13] and other stakeholders exert pressure on the implementation of environmental behavior from the outside, urge enterprises to take the initiative to implement environmental behavior and increase the performance of environmental operations. Some scholars also consider the subjective initiative of enterprises, from the enterprise's own factors, to study the influence of the size of enterprises [14-16], organizational redundancy [17], financial situation [18, 19], Green technology [20, 21] and leader values [22, 23]. These studies are of great significance to reveal the influence mechanism of corporate environmental behavior. However, some studies have found that the level of corporate environmental behavior has not improved when the investment of scientific researchers is large, and the intensity of environmental regulations is high [24]. So, are there any other factors that influence the decision-making of environmental behavior? The theory of organization and management holds that under the same or similar institutional environment, the difference of organizational culture and knowledge sharing within the enterprise will also lead to the difference of environmental behavior of the enterprise $[25,26]$. Enterprises pay more and more attention to the improvement of environmental protection knowledge and sharing mechanism. However, the existing research focuses on the impact of knowledge sharing on enterprise innovation performance and financial performance $[27,28]$. There is a lack of proper research on the driving effect of organizational sharing on enterprise environmental behavior.

In addition, does the driving factor of enterprise environmental behavior directly affect the choice of enterprise environmental behavior? Based on the theory of planned behavior, scholars find that environmental will is the direct premise of behavior and is influenced by three factors: attitude toward the behavior, subject norm and perceived behavior control [29]. At present, some scholars study the green innovation will of enterprises based on the theory of planned behavior. For example, Wang took high-end manufacturing as an example to conduct research [30], and the results showed that the will of green technology innovation played an intermediary role between subjective norms and corporate green innovation activities; Tian analysis from the individual level, it is found that environmental will has a positive effect on the environmental behavior and voluntary employee behavior of employees [31]. However, there is a lack of due research on the intermediary role of enterprise environmental will.

Although the research of domestic and foreign scholars has analyzed many factors that affect the environmental behavior of enterprises from different angles, it still needs to be deepened. First, the company is in an extremely complex environment, and many factors will have a dynamic and interactive impact on the company's environmental behavior, but the existing research lacks a combing of the mechanism of action among multiple factors. Second, although some scholars use the theory of planned behavior as the basis for explaining corporate environmental behavior, they focus on the direct impact of environmental attitudes on environmental behavior, and rarely introduce environmental will as an intermediary variable. Third, the adjustment mechanism of organizational sharing on corporate environmental behavior is not clear and needs further discussion. Therefore, based on the mature planning behavior theory, this paper constructs the research framework and model path, introduces corporate environmental will as intermediary variable, knowledge sharing and corporate social responsibility as regulating variables, and systematically discusses the internal modes of corporate reputation, market profits, leader awareness, technical support and so on.

\section{Material and Methods}

\section{Planning Behavior Theory and Research Hypotheses}

The theory of Planned Behavior (TPB) is proposed based on the expected value theory, which explains the driving factors of individual behavior from the perspective of information processing [32, 33]. This theory is extended by Ajzen on the basis of Theory of Reasoned Action (TRA), he believes that variables indirectly affect behavior performance by influencing behavior intention, and behavior intention is affected by three variables: Attitude toward The Behavior (AB), Subject Norm (SN) and Perceived Behavior Control (PBC) [29]. After the TPB theory was proposed, it has been widely used in the interpretation of individual behavior, providing a theoretical basis for many studies. As a microscopic entity, an enterprise should follow the TPB theory for its behavioral decision-making. Thomas A research based on TPB theory shows that environmental will positively affects environmental behavior, and green atmosphere plays a positive role in regulating environmental behavior [34]. Based on the theory of planning behavior, Xie found that the green behavior of resource-based enterprises was positively correlated with green cognition, resource ability, cooperation expectation and social network [35]. Based on the above scholars' research and the actual situation of the investigated enterprises, this paper takes the TPB theory as the path to explain the mechanism of environmental behavior of enterprises.

Market Profits (Market Profits, MP) positively affects the environmental will and behavior of enterprises. TPB theory holds that behavior attitude mainly focuses on the behavior subject's love degree and expected evaluation of specific behavior, and can influence behavior intention through the intermediary role of behavior intention [36]. The main motive force 
for enterprises to carry out environmental behavior is profit motive. If enterprises carry out green production to bring considerable market income, it will produce external positive feedback mechanism to enterprises. The more positive the attitude of enterprises to implement environmental behavior, the more significant the effectiveness of environmental operations, the stronger the environmental will of enterprises. Dietrich studied the relationship between the financial situation of enterprises and the environmental behavior of enterprises in the transition economy, and found that enterprises with good financial situation are more likely to take the initiative to adopt environmental behavior [18]. Zou believed that market expansion and profit enhancement can promote green production, while enterprises can bring long-term benefits by improving environmental behavior [37]. To sum up, this paper proposes the hypothesis H1a and the hypothesis H2a:

H1a:Market Profits positively affect Corporate Environmental Will

H2a:Market Profits positively affect Corporate Environmental Behavior

Corporate Reputation (CR) positively affects the environmental will and behavior of enterprises. As contributors to GDP, enterprises are also "triggers" of environmental disputes [38]. In order to urge enterprises to assume environmental responsibilities, the government imposes strict environmental control on enterprises, and mass media and communities also exercise strong public opinion supervision over enterprises. The will of an enterprise to maintain a good reputation to meet external expectations will promote the implementation of its environmental behavior. According to TPB theory, subjective norms can be divided into directive norms (Directive Norm) and exemplary norms (Model Norm). In essence, prescriptive norms are perceived expectations of others and organizations that favor or oppose, forcing firms to constantly regulate their own behavior. As an enterprise, the social reputation pressure from government, community and other stakeholders can be interpreted as prescriptive norms. Xiang and Vera [39-40] both verify the external incentive effect of corporate reputation on the implementation of environmental behavior. On the basis of the above analysis, this paper presents the hypothesis $\mathrm{H} 1 \mathrm{~b}$ and hypothesis $\mathrm{H} 2 \mathrm{~b}$ :

H1b:Corporate Reputation positively affects Corporate Environmental Will

H2b:Corporate Reputation positively affects Corporate Environmental Behavior

Leader Awareness (LA) positively affects the environmental will and behavior of enterprises. Leader awareness can be understood as the exemplary norms of environmental behavior implemented by employees, and the exemplary norms emphasize the individual's perception of the behavior of others. Whether the employees carry out environmental behavior is related to the behavior concept of others in the organizational environment, especially leader awareness. Therefore, the concept of green production and green $R \& D$ plays an important role in the choice of environmental behavior of employees. Saleem found that the leader consciousness positively affects the green behavior through the green psychological climate regulation function [41]. And Mo took China's heavily polluted listed companies as the object of investigation, and concluded that the stronger the leader awareness, the positive regulation effect of environmental values on the relationship between environmental behavior and environmental performance is more obvious [42]. Business managers who take the initiative to assume environmental responsibility and develop relevant strategies can stimulate employees' will to implement environmental behavior and translate it into practical action. On the basis of the above analysis, this paper proposes the hypothesis H1c and the hypothesis H2c:

H1c:Leader Awareness positively affects Corporate Environmental Will

H2c:Leader Awareness positively affects Corporate Environmental Behavior

Technical support (TS) positively affects the environmental will and behavior of enterprises. Enterprises may encounter obstacles in technical resources when implementing environmental behaviors. If a company wants to achieve green production, it must invest a lot of money to purchase environmental protection equipment and introduce energy-saving technologies, and there are uncertainties and complexities in technological innovation. Therefore, enterprises will face a lot of unknown difficulties [43]. The pressure of environmental behavior felt by enterprises can be interpreted as perceptual behavior control. According to the results of the questionnaire, only $19.88 \%$ of the surveyed enterprises actively introduced advanced environmental protection technologies, which shows that technology is a bottleneck in the process of green development of enterprises. When enterprises seek the necessary technical support to carry out environmental behavior, the binding force of green production behavior is smaller, which can stimulate the environmental will of enterprises. To sum up, this paper proposes hypothesis H1d and hypothesis H2d:

H1d:Technology Support positively affect Corporate Environmental Will

H2d:Technical Support positively affect Corporate Environmental Behavior

From the above analysis of the relationship between attitude toward the behavior, subjective norms and perceived behavioral control, the higher the expected market profits, the greater the pressure of public opinion expectation, and the stronger the leader's awareness of green environmental protection. The higher the technical support for green innovation, the more Corporate Environmental Will (CEW) can be stimulated. Li and Wang have both verified the mediating role of environmental will between environmental attitudes and environmental behaviors [30-31]. As a result, this paper proposes hypothesis $\mathrm{H} 3 \mathrm{a}-\mathrm{H} 3 \mathrm{~d}$ : 
H3a: Corporate Environmental Will plays an intermediary role between Corporate Reputation and Corporate Environmental Behavior

H3b: Corporate Environmental Will plays an intermediary role between Leader Awareness and Corporate Environmental Behavior

H3c: Corporate Environmental Will plays an intermediary role between technical support and Corporate Environmental Behavior

H3d: Corporate Environmental Will plays an intermediary role between Market Profits and Corporate Environmental Behavior

Knowledge Sharing (KS), as an important way for enterprises to build knowledge-based competitive advantages, is an important link in the transformation of individual knowledge into organizational or team knowledge, and it is also a prerequisite for knowledge creation [44]. Through empirical research, $\mathrm{He}$ and Wang find that knowledge sharing among individual employees is not a spontaneous process, and information asymmetry exists between employees and business leaders [45]. The reason is that employees are both providers and recipients of knowledge, and there are obstacles to effective knowledge expression and adequate information reception [46]. The lack of information is not conducive to the effective integration of resources and conflict resolution of corporate employees, and it is also not conducive to the transformation of leader awareness to environmental will. Based on the above analysis, this paper proposes hypothesis $\mathrm{H} 4$ :

H4:Knowledge Sharing plays a moderating role between Leader Awareness and Corporate Environmental Will

As the main body of profit-seeking, enterprises are prone to negative externalities or moral hazard behavior, thus harming the interests of various stakeholders. Freeman define Corporate Social Responsibility (CSR) as the responsibility of the enterprise to all stakeholders, including employees, suppliers, customers, government and the community [47]. On this basis, $\mathrm{Xu}$ extended the dimension of corporate social responsibility to include environmental responsibility [48]. Corporate responsibility in this paper mainly emphasizes environmental responsibility. It is the ethical behavior of many stakeholders to fulfill social responsibility in the realization of economic interests. Enterprises that actively undertake social responsibility are more likely to meet the demands of stakeholders such as community media, thus putting more costs into green production and innovation activities, and promoting environmental will into practical action $[49,50]$. As a result, this paper presents hypothesis H5:

H5: Corporate Social Responsibility plays a moderating role between Corporate Environmental Will and Corporate Environmental Behavior

Based on the above assumptions, this paper constructs a structural equation model of enterprise environmental behavior drivers, as shown in Fig. 1.

\section{Research Methods and Processes}

\section{Measurement of Variables}

The questionnaire designed in this study is mainly divided into three parts, the first part is the basic situation of the investigated enterprises. This part consists of 8 items, including the size of the enterprise visited, the sex of the interviewee, the type and scale of the family, the income and years of work and the type of work of interviewee, and the second part is the factors that affect the environmental behavior of the enterprise. There are 24 items in this part, including Market Profits (MP), Corporate Reputation (CR), leader Awareness (LA) and Technical Support (TS) measurement reference

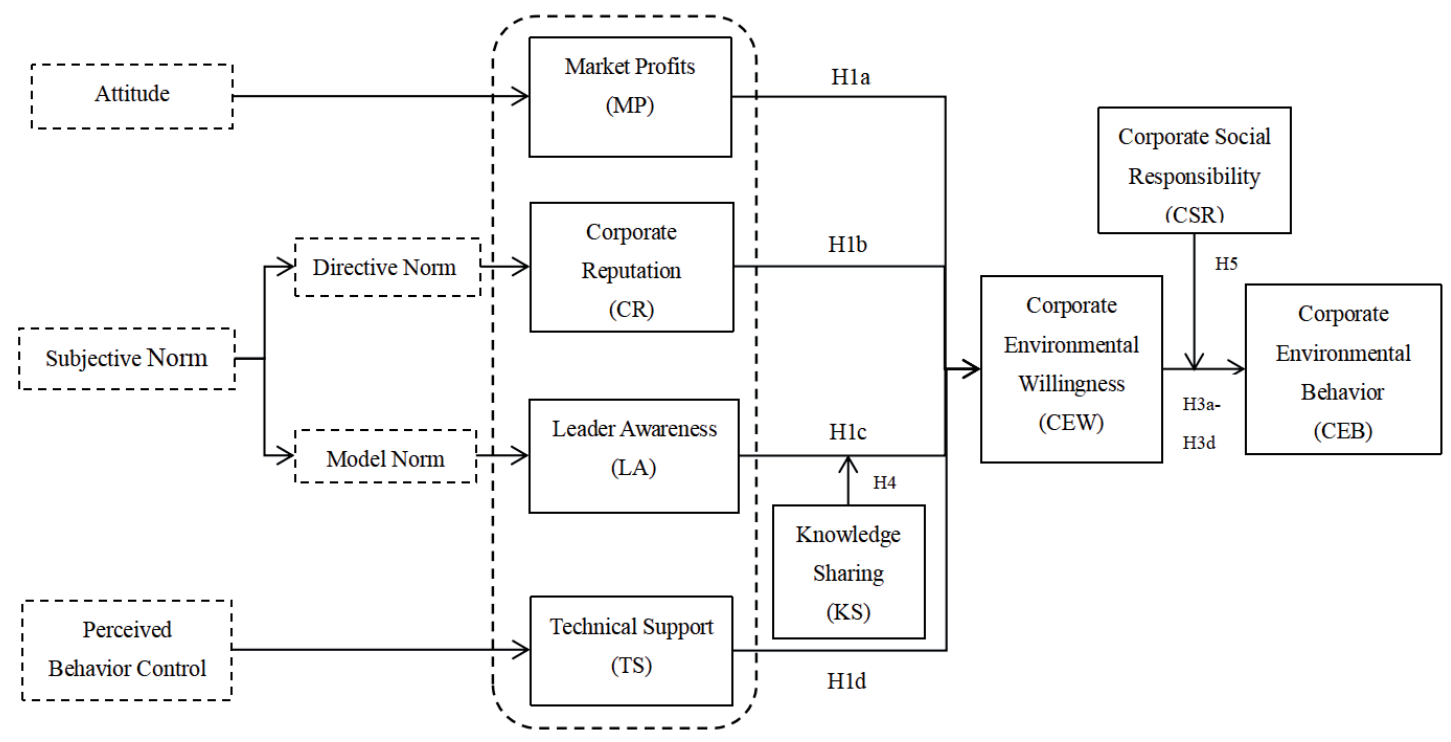

Fig. 1. Structure equation model of environmental behavior drivers in enterprises. 
Table 1. Measurement criteria for the scale.

\begin{tabular}{|c|c|c|}
\hline Variable & Serial number & Measurement indicators \\
\hline \multirow{4}{*}{$\begin{array}{l}\text { Corporate } \\
\text { Reputation } \\
\quad(\mathrm{CR})\end{array}$} & CR1 & Companies believe that preventing pollution scandals is one of their goals \\
\hline & CR2 & $\begin{array}{l}\text { When bad pollution and other incidents occur, company's top executives think this is a major } \\
\text { event related to corporate reputation and image building }\end{array}$ \\
\hline & CR3 & $\begin{array}{l}\text { Maintaining communication with the news media on environmental image is a constant practice } \\
\text { for companies }\end{array}$ \\
\hline & CR4 & $\begin{array}{l}\text { Does the company attach importance to the formulation of environmental policies such as em- } \\
\text { ployee environmental knowledge training, internal and external environmental audit, environmen- } \\
\text { tal accounting, corporate environmental reporting, etc }\end{array}$ \\
\hline \multirow{4}{*}{$\begin{array}{l}\text { Leader } \\
\text { Awareness } \\
\quad(\text { LA) }\end{array}$} & LA1 & Enterprise strategy tends to environment-friendly development \\
\hline & LA2 & The concept of sustainable development has been emphasized in enterprise development strategies \\
\hline & LA3 & Does the company's top management value environmental protection \\
\hline & LA4 & Whether the company will deal with the negative impact of the pollution scandal in time \\
\hline \multirow{2}{*}{$\begin{array}{l}\text { Technical } \\
\text { Support } \\
\text { (TS) }\end{array}$} & TS1 & $\begin{array}{l}\text { Enterprises actively introduce all kinds of advanced energy-saving technologies and use environ- } \\
\text { mental protection equipment }\end{array}$ \\
\hline & TS2 & $\begin{array}{l}\text { The top management of the enterprise has always insisted on adopting the most advanced energy } \\
\text { saving and environmental protection technology }\end{array}$ \\
\hline \multirow{3}{*}{$\begin{array}{l}\text { Market Profits } \\
\quad(\mathrm{MP})\end{array}$} & MP1 & Corporate financial performance and environmental indicators are closely linked \\
\hline & MP2 & Corporate leaders pay close attention to environmental performance indicators \\
\hline & MP3 & $\begin{array}{l}\text { The concept of balanced development of enterprise economic interests and environmental security } \\
\text { has always been emphasized and practiced }\end{array}$ \\
\hline \multirow{2}{*}{$\begin{array}{l}\text { Corporate } \\
\text { Environmental } \\
\text { Will } \\
(\mathrm{CEW}) \\
\end{array}$} & CEW1 & Enterprises have been advocating encouraging the conservation of electricity and water \\
\hline & CEW2 & $\begin{array}{c}\text { Enterprises actively encourage the use of environmental protection and innovation technology in } \\
\text { enterprises }\end{array}$ \\
\hline \multirow{4}{*}{$\begin{array}{l}\text { Corporate } \\
\text { Environmental } \\
\text { Behavior } \\
\text { (CEB) }\end{array}$} & CEB1 & $\begin{array}{l}\text { Most of the raw materials, office supplies (such as production water, paper) used by enterprises are } \\
\text { reusable environmental materials }\end{array}$ \\
\hline & CEB2 & $\begin{array}{l}\text { In the enterprise production process, according to the ecological green manufacturing process } \\
\text { implementation }\end{array}$ \\
\hline & CEB3 & Enterprises have special pollution supervision departments and clear responsibilities \\
\hline & CEB4 & $\begin{array}{l}\text { Enterprises earnestly implement and emphasize environmental protection work such as resource } \\
\text { saving, garbage sorting and pollution monitoring }\end{array}$ \\
\hline \multirow{5}{*}{$\begin{array}{l}\text { Knowledge } \\
\text { Sharing } \\
\text { (KS) }\end{array}$} & KS1 & Enterprises regularly conduct environmental awareness, knowledge and skills training \\
\hline & $\mathrm{KS} 2$ & $\begin{array}{l}\text { Enterprises pay attention to saving, long-term training activities to repair the old and waste, fear } \\
\text { life }\end{array}$ \\
\hline & KS3 & Does the enterprise advocate environmental marketing and environmental culture \\
\hline & KS4 & $\begin{array}{l}\text { Whether enterprises attach importance to green building design, energy conservation management, } \\
\text { water conservation management, waste discharge management }\end{array}$ \\
\hline & KS5 & $\begin{array}{l}\text { Do enterprises attach importance to environmental management communication and environmen- } \\
\text { tal knowledge }\end{array}$ \\
\hline \multirow{6}{*}{$\begin{array}{l}\text { Corporate Social } \\
\text { Responsibility } \\
\text { (CSR) }\end{array}$} & CSR1 & Corporate executives believe that social responsibility is always the responsibility of enterprises \\
\hline & CSR2 & Enterprises have been punished by the relevant departments for various pollution acts \\
\hline & CSR3 & $\begin{array}{l}\text { What kind of energy conservation, environmental protection or green title has the enterprise } \\
\text { obtained }\end{array}$ \\
\hline & CSR4 & $\begin{array}{l}\text { Reducing and eliminating pollution incidents such as oil spills and pollution emissions has always } \\
\text { been an important concern for enterprises }\end{array}$ \\
\hline & CSR5 & Security of the surrounding community \\
\hline & CSR6 & $\begin{array}{l}\text { Efforts have been made to make environmental information transparent, such as energy conserva- } \\
\text { tion and emission reduction information }\end{array}$ \\
\hline
\end{tabular}


Ajzen TPB theory modification [29]. Measurement of Knowledge Sharing (KS) with reference to the scale of Yang [20]. Measurement of Corporate Social Responsibility (CSR) reference to $\mathrm{Xu}$ [48]. The third part is the investigation of Corporate Environmental Will (CEW) and Corporate Environmental Behavior (CEB). This part includes 6 items, which are modified based on Qi's scale to evaluate the implementation of environmental behavior of enterprises from the aspects of green innovation, green production and pollution supervision [51].

In order to ensure the scientific and effective measurement of variables, Before the formal investigation, this paper carried out a preliminary investigation on 15 resource-based enterprises in Xuzhou, The preliminary survey was conducted in March 2019 in the form of a questionnaire, A total of 350 questionnaires were distributed, and there were 267 valid questionnaires. According to the information of pre-check feedback, the reliability and validity of the scale are tested, and on this basis, the items are eliminated and modified step by step, and the formal contents of this study are finally determined. Form a final scale of 38 items (see Table 1).

\section{Data Collection}

This paper mainly studies the environmental will and behavior of resource-based enterprises. As a typical old industrial base and resource city in the country, Xuzhou city is in the critical moment of industrial green transformation, the contradiction between environmental benefit and economic benefit is more prominent. It is an ideal research sample. The official investigation was conducted in June 2019, the graduate students of Jiangsu Normal University investigated 26 enterprises of different sizes in Xuzhou. The subjects were coal, steel, petrochemical, metallurgical energy and other resources of different sizes. Because the management of the enterprise has a better understanding of the implementation of environmental protection strategy and environmental behavior, as a result, paper questionnaires were distributed to senior, middle and grass-roots managers, completed on the spot and recovered immediately, a total of 550 questionnaires were distributed, eliminated multiple options, there were no differences in the answers and 47 missing questionnaires, 503 valid questionnaires, the effective rate is $91.45 \%$. The characteristics of the sample structure are described in Table 2.

\section{Reliability and Validity Test}

The results of reliability analysis by Cronbach's $\alpha$ coefficient are shown in Table 3. The Cronbach's $\alpha$ values of each scale and the whole scale of environmental behavior are higher than 0.9. According to the principle of "Cronbach's $\alpha$ coefficient is higher than 0.8 , the scale has good internal consistency", which indicates that the reliability level of sample data is high.

Besides, based on exploratory factor analysis, this paper tests the validity and goodness of fit, concrete use of SPSS software, KMO test of sample data and Bartlett sphericity test, as can be seen from Table 3, the KMO values of each variable are greater than 0.6 , and all passed the bartlett sphericity test. It shows that there is a strong correlation between the variables, it is suitable for factor analysis. And then using principal component

Table 2. Description of sample structure features.

\begin{tabular}{|c|c|c|c|}
\hline \multirow{2}{*}{ Project } & Type & Number of persons & Percentage \\
\hline \multirow{3}{*}{ Gender } & Male & 226 & $44.93 \%$ \\
\cline { 2 - 4 } & Female & 277 & $55.07 \%$ \\
\hline \multirow{4}{*}{ Working years } & Within 5 years & 202 & $40.16 \%$ \\
\cline { 2 - 4 } & $5-10$ years & 147 & $29.22 \%$ \\
\cline { 2 - 4 } & More than 20 years & 86 & $17.10 \%$ \\
\hline \multirow{3}{*}{ Size of the enterprise } & Oversize & 68 & $13.52 \%$ \\
\cline { 2 - 4 } & Large scale & 139 & $27.64 \%$ \\
\cline { 2 - 4 } & Medium & 115 & $22.86 \%$ \\
\cline { 2 - 4 } & Small & 102 & $20.28 \%$ \\
\cline { 2 - 4 } & Miniature & 115 & $22.86 \%$ \\
\hline \multirow{3}{*}{ Enterprise management } & Top management & 32 & $6.36 \%$ \\
\hline & Middle managers & 203 & $40.36 \%$ \\
\hline
\end{tabular}


Table 3. Test results of reliability and validity of each scale.

\begin{tabular}{|c|c|c|c|c|}
\hline Variable & $\begin{array}{c}\text { Number of } \\
\text { items }\end{array}$ & $\begin{array}{c}\text { Cronbach's } \alpha \\
\text { coefficient }\end{array}$ & KMO value & $\begin{array}{c}\text { Cumulative explanatory } \\
\text { variance }\end{array}$ \\
\hline Corporate Reputation (CR) & 4 & 0.912 & 0.856 & $79.096 \%$ \\
\hline Leader Awareness (LA) & 4 & 0.914 & 0.846 & $79.544 \%$ \\
\hline Technical Support (TS) & 2 & 0.930 & 0.763 & $86.729 \%$ \\
\hline Market Profits (MP) & 3 & 0.882 & 0.738 & $80.920 \%$ \\
\hline Corporate Environmental Will (CEW) & 2 & 0.862 & 0.844 & $87.857 \%$ \\
\hline Corporate Environmental Behavior (CEB) & 4 & 0.896 & 0.830 & $76.434 \%$ \\
\hline Knowledge Sharing (KS) & 5 & 0.931 & 0.904 & $78.505 \%$ \\
\hline Corporate Social Responsibility (CSR) & 6 & 0.926 & 0.920 & $73.860 \%$ \\
\hline Overall Reliability Scale & 30 & 0.985 & & \\
\hline
\end{tabular}

analysis, the orthogonal rotation of factor load matrix is carried out by variance maximization method, according to Tables 3 and 4, the percentage of variance explained by all item variables is higher than $70 \%$, conforms to the standard of variance interpretation ratio greater than $50 \%$. The standard factor load number of each measurement index is greater than 0.5 in each variable, it shows that it has good convergence validity. The standard factor load of each measurement index in other variables is less than 0.5 , it shows that it has good differential validity. To sum up, validity test passed [52].

\section{Results and Discussion}

In order to verify the relationship between the indicator variables in the analytical framework, AMOS software is used to test the resulting structural equation model, according to the initial results, the non-significant path of "leader awareness (corporate environmental behavior", "corporate reputation (corporate environmental behavior" are removed in turn, and the final model shown in Fig. 2 is obtained. Each index of the model is: RMSEA $=0.075$, meet the standard below 0.08. GFI $=0.938$, TLI $=0.930$, $\mathrm{CFI}=0.940$, the specified value is greater than 0.9 . According to AMOS evaluation criteria for model fitting index, the model fits well [53].

\section{Environmental Behavior Drivers Test}

The model path coefficient and model fitting test results are shown in Table 5, market profits positively affect corporate environmental will $(\beta=0.473$, $\mathrm{t}=3.812$ ), hypothesis H1a verified. Corporate reputation positively affects corporate environmental

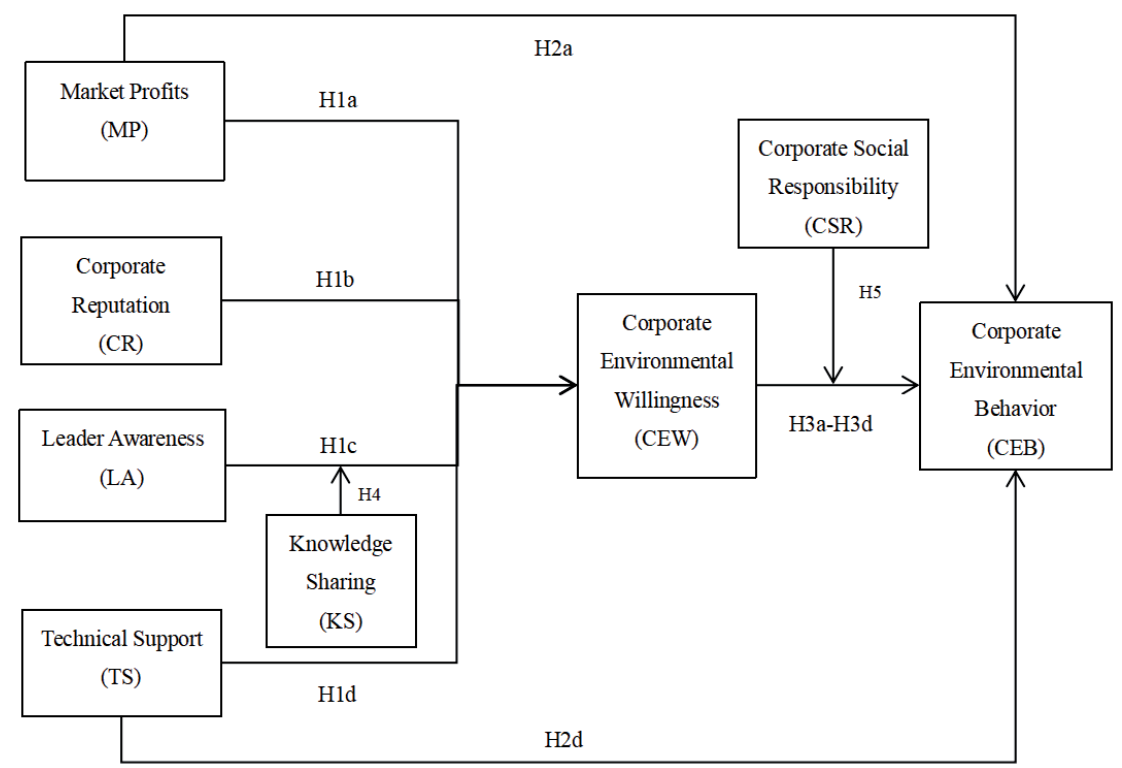

Fig. 2. Final model of enterprise environmental behavior drivers. 
Table 4. Validation factor analysis test results.

\begin{tabular}{|c|c|c|}
\hline Variable & Path & $\begin{array}{c}\text { Standard factor } \\
\text { load factor }\end{array}$ \\
\hline \multirow{4}{*}{$\begin{array}{l}\text { Corporate Reputation } \\
\text { (CR) }\end{array}$} & CR $1<--$ CR & 0.830 \\
\hline & $\mathrm{CR} 2<--\mathrm{CR}$ & 0.851 \\
\hline & CR3<-- CR & 0.861 \\
\hline & CR4<-- CR & 0.857 \\
\hline \multirow{4}{*}{ Leader Awareness (LA) } & LA $1<-$ LA & 0.849 \\
\hline & LA2 $<--$ LA & 0.844 \\
\hline & LA3<-- LA & 0.861 \\
\hline & LA4<-- LA & 0.857 \\
\hline \multirow{2}{*}{ Technical Support (TS) } & TS1<-- TS & 0.862 \\
\hline & TS2<-- TS & 0.852 \\
\hline \multirow{3}{*}{ Market Profits (MP) } & MP1<-- MP & 0.853 \\
\hline & MP2<-- MP & 0.858 \\
\hline & MP3<-- MP & 0.827 \\
\hline \multirow{2}{*}{$\begin{array}{l}\text { Corporate Environmental } \\
\text { Will (CEW) }\end{array}$} & CEW $1<--$ CEW & 0.874 \\
\hline & CEW2<-- CEW & 0.866 \\
\hline \multirow{4}{*}{$\begin{array}{c}\text { Corporate Environmental } \\
\text { Behavior (CEB) }\end{array}$} & CEB $1<-$ CEB & 0.728 \\
\hline & CEB2<-- CEB & 0.839 \\
\hline & CEB3<-- CEB & 0.857 \\
\hline & CEB4<-- CEB & 0.878 \\
\hline \multirow{5}{*}{ Knowledge Sharing (KS) } & KS1<-- KS & 0.829 \\
\hline & $\mathrm{KS} 2<--\mathrm{KS}$ & 0.877 \\
\hline & $\mathrm{KS} 3<--\mathrm{KS}$ & 0.862 \\
\hline & KS4<-- KS & 0.831 \\
\hline & KS5<-- KS & 0.887 \\
\hline \multirow{6}{*}{$\begin{array}{c}\text { Corporate Social } \\
\text { Responsibility (CSR) }\end{array}$} & CSR $1<--$ CSR & 0.849 \\
\hline & CSR2<-- CSR & 0.738 \\
\hline & CSR3<-- CSR & 0.831 \\
\hline & CSR4<-- CSR & 0.853 \\
\hline & CSR5<-- CSR & 0.854 \\
\hline & CSR6<-- CSR & 0.848 \\
\hline
\end{tabular}

will $(\beta=0.760, \mathrm{t}=2.375)$, hypothesis $\mathrm{H} 1 \mathrm{~b}$ verified. Leader awareness positively influences corporate environmental will $(\beta=0.889, \mathrm{t}=3.340)$, hypothesis H1c verified. Technical support positively impacts corporate environmental will $(\beta=0.459, \mathrm{t}=6.202)$, hypothesis H1d is verified. Market profits positively affect corporate environmental behavior $(\beta=0.149$, $\mathrm{t}=2.604)$, technical support positively impacts corporate environmental behavior $(\beta=0.106, t=1.970)$, and neither leader awareness nor corporate reputation has a significant effect on corporate environmental
Table 5. Path coefficient of model and test results of model fitting.

\begin{tabular}{|c|c|c|c|}
\hline Path path & $\begin{array}{c}\text { Path } \\
\text { coefficient }\end{array}$ & T value & $\begin{array}{c}\text { Support } \\
\text { for assumptions }\end{array}$ \\
\hline CEW $<-$ MP & $0.473^{* * *}$ & 3.812 & Support \\
\hline CEW $<-$ TS & $0.459 * * *$ & 6.202 & Support \\
\hline CEW $<-$ LA & $0.889 * * *$ & 3.340 & Support \\
\hline CEW $<-$ CR & $0.760^{* * *}$ & 2.375 & Support \\
\hline CEB $<-$ CEW & $0.677 * * *$ & 7.272 & Support \\
\hline $\mathrm{CEB}<-$ TS & $0.106^{*}$ & 1.970 & Support \\
\hline $\mathrm{CEB}<-$ LA & 0.189 & 1.036 & No support \\
\hline $\mathrm{CEB}<-$ CR & 0.368 & 0.903 & No support \\
\hline $\mathrm{CEB}<-$ MP & $0.149^{* *}$ & 2.604 & Support \\
\hline
\end{tabular}

Note: $*$ indicates $\mathrm{p}<0.05, * *$ indicates $\mathrm{p}<0.01, * * *$ indicates $\mathrm{p}<0.001$

behavior, $\mathrm{H} 2 \mathrm{a}$ and $\mathrm{H} 2 \mathrm{~d}$ is verified. Corporate environmental will positively affects corporate environmental behavior $(\beta=0.677, t=7.272)$, hypothesis $\mathrm{H} 3 \mathrm{a}$, hypothesis $\mathrm{H} 3 \mathrm{~b}$, hypothesis H3c, hypothesis H3d are verified.

\section{Intermediation Test of Corporate Environmental Will}

Intermediary variables, also known as intermediate variables, play a media role between independent variables and dependent variables. When a variable can explain the relationship between independent variable and dependent variable, it is considered that the variable plays an intermediary effect between independent variable and dependent variable [54]. In this paper, regression 1 to regression 4 are constructed to examine the mediating effects of corporate environmental will in the path of corporate reputation, leader awareness, technical support and market profits. The first step is to investigate the relationship between independent variables and dependent variables, the second step is to investigate the relationship between independent variables and intermediary variables, the third step is to investigate the relationship between intermediary variables and dependent variables, the fourth step is to analyze the influence of independent variables on dependent variables. As shown in Table 6, the first three steps of regression 1 to regression 4 are significant. In the fourth step, the path coefficient of regression 1 and regression 2 intermediary variables is significant, while the path coefficient of independent variable to dependent variable is not significant, so corporate environmental will plays a full intermediary role in the path of enterprise reputation and leader consciousness income affecting environmental behavior; regression 3 and regression 4 intermediary variable path coefficient is significant at the same time independent variable to 


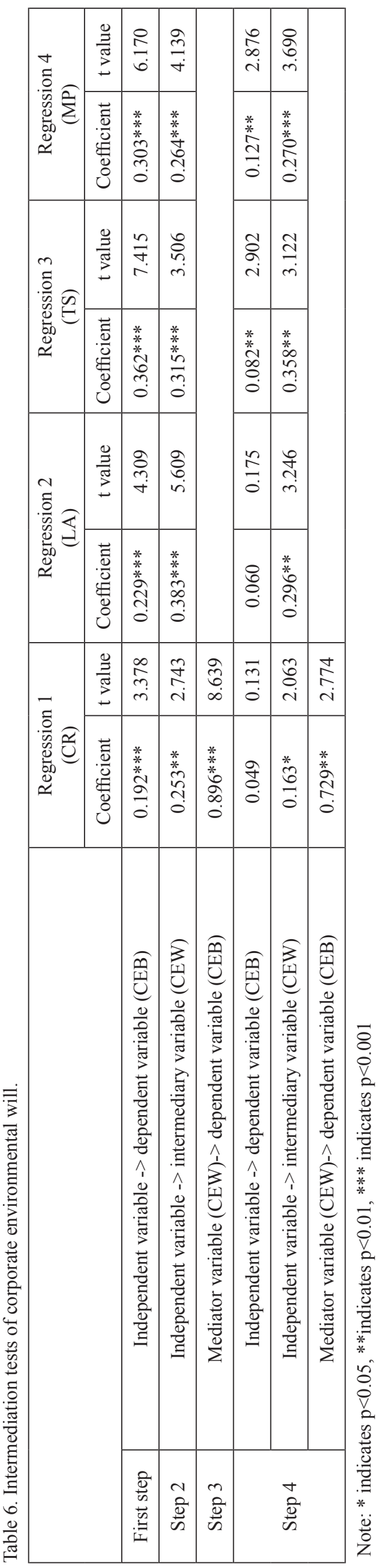

intermediary variable path is significant, independent variable to dependent variable path coefficient is significant, but the coefficient value is smaller than before, then corporate environmental will plays a part intermediary role in the path of technical support, market profits affecting corporate environmental behavior.

Testing of the Regulatory Role of Knowledge Sharing and Corporate Social Responsibility

A regulatory variable is a special independent variable that acts as an independent variable, also known as a sub-independent variable (Secondary independent variable) [55]. The regulatory variable examines the conditions under which the independent variable affects the dependent variable, including the direction and extent of the adjustment. The test of regulation effect is to measure whether the causality between independent variable and dependent variable changes with the value of regulating variable. Regression analysis and structural equation model are the usual analytical methods for regulating variables [53].

Test the regulatory role of knowledge sharing. In order to verify the hypothesis that knowledge sharing plays a regulatory role between leader awareness and corporate environmental will, this paper uses the hierarchical regression analysis method in SPSS software to test the regulatory effect of knowledge sharing, taking leader awareness as independent variable, corporate environmental will as a dependent variable. The first step is to introduce the gender, working life, type of work and enterprise scale into the regression equation, the second step is to introduce the independent variable and the adjusting variable into the regression equation, and the third step is to introduce the interaction between the independent variable and the adjusting variable into the regression equation. The results are shown in Table 6, the regression coefficient of knowledge sharing on corporate environmental behavior is 0.538 , and the regression coefficient of the interaction item between knowledge sharing and leader awareness on environmental behavior is 0.617 , and the p-values are all less than 0.001, reaching a significant level, assuming $\mathrm{H} 3$ a Be verified.

The regulation of corporate social responsibility. The analytic hierarchy process is also used to test the hypothesis that corporate social responsibility plays a regulatory role between environmental will and environmental behavior. The environmental will as independent variable, environmental behavior as dependent variable, social responsibility as regulatory variable, and controlling demographic characteristics. As shown in Table 7, the regression coefficient of social responsibility to environmental behavior is 0.398 and the $\mathrm{p}$ value is less than 0.001 . However, the interaction term between corporate social responsibility and environmental will is not significant for the regression 
Table 7. The moderating role of knowledge sharing between leader awareness and corporate environmental will.

\begin{tabular}{|c|c|c|c|}
\hline Variable & Model 1 & Model 2 & Model 3 \\
\hline 1. Gender & $0.269^{* *}$ & 0.036 & 0.036 \\
\hline Working years & $0.086^{*}$ & 0.024 & -0.018 \\
\hline Type of work & 0.023 & -0.017 & -0.021 \\
\hline Size of the enterprise in which it is located & -0.030 & -0.020 & $0.346^{* * *}$ \\
\hline 2. Leader awareness & & $0.344^{* * *}$ & $0.538^{* * *}$ \\
\hline Knowledge sharing & & $0.533^{* * *}$ & $0.617^{* * *}$ \\
\hline 3. Leader awareness $\times$ knowledge sharing & & $31.775^{* * *}$ & $35.945^{* * *}$ \\
\hline$\Delta \mathrm{F}$ & $33.780^{* *}$ & 0.753 & 0.753 \\
\hline $\mathrm{R}^{2}$ & 0.029 & 0.750 & 0.750 \\
\hline $\mathrm{IR}^{2}$ & 0.022 & & \\
\hline
\end{tabular}

Note: $*$ indicates $\mathrm{p}<0.05, * *$ indicates $\mathrm{p}<0.01, * * *$ indicates $\mathrm{p}<0.001$

Table 8 . The moderating role of corporate social responsibility between environmental will and environmental. behavior.

\begin{tabular}{|c|c|c|c|}
\hline Variable & Model 1 & Model 2 & Model 3 \\
\hline 1. Gender & $0.335^{* * *}$ & $0.084^{*}$ & $0.084^{*}$ \\
\hline Working years & $0.120^{* *}$ & $0.057^{* *}$ & $0.057^{* *}$ \\
\hline Type of work & 0.016 & -0.001 & -0.001 \\
\hline Size of the enterprise in which it is located & -0.023 & -0.002 & -0.002 \\
\hline 2. Corporate environmental will & & $0.533^{* * *}$ & $0.533^{* * *}$ \\
\hline Corporate social responsibility & & $0.398^{* * *}$ & $0.398^{* * *}$ \\
\hline 3. Corporate environmental will $\times$ corporate social responsibility & & & 0.261 \\
\hline$\Delta \mathrm{F}$ & $36.135^{*}$ & $32.810^{* *}$ & $35.222^{*}$ \\
\hline $\mathrm{R}^{2}$ & 0.047 & 0.812 & 0.812 \\
\hline $\mathrm{IR}^{2}$ & 0.039 & 0.810 & 0.809 \\
\hline
\end{tabular}

Note: * indicates $\mathrm{p}<0.05, * *$ indicates $\mathrm{p}<0.01, * * *$ indicates $\mathrm{p}<0.001$

of corporate environmental behavior, so the hypothesis $\mathrm{H} 3 \mathrm{~b}$ fails the test.

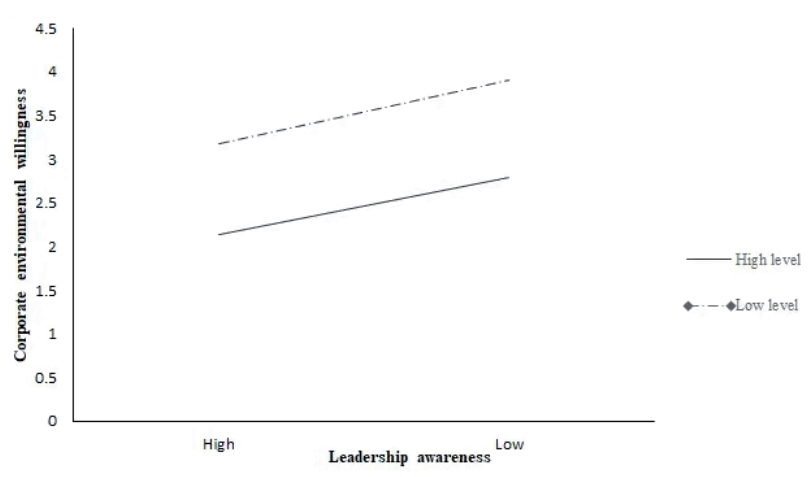

Fig. 3. The regulation of knowledge sharing on leadership awareness and environmental willingness.
To further test the direction of knowledge sharing between leader awareness and corporate environmental will, this paper adopts Aiken and West methods [56], and classifies the knowledge sharing of adjusting variables according to the average value plus or minus one standard deviation, that is, greater than knowledge sharing plus one standard deviation as higher knowledge sharing level, lower than knowledge sharing minus one standard deviation as lower knowledge sharing level. And two regression equations are obtained: $\mathrm{Y}_{1}=0.423 \mathrm{X}+5.423, \mathrm{Y}_{2}=0.389 \mathrm{X}+4.362$, the results are shown in Fig. 3. By comparing the slope of regression equation graph line, it can be found that the slope of higher knowledge sharing level line is larger than that of lower knowledge sharing level, which shows that knowledge sharing is more positive. 


\section{Conclusions}

Based on the research data of 503 Xuzhou resourcebased enterprises, this paper synthesizes the internal and external factors that affect the environmental will and behavior of enterprises from three aspects: behavior attitude, subjective norm and perceived behavior control, systematically analyzes the mechanism of environmental behavior decision-making as microindividual, and constructs a structural equation model to demonstrate the relevant assumptions, that is, positive expected market profits, greater pressure of public opinion expectation, strong environmental protection consciousness of leaders, and the more complete green innovation ability of enterprises have a positive impact on corporate environmental will, thereby promoting corporate environmental behavior. The study found that:

The influence coefficient of leader awareness on corporate environmental will is 0.889 , which explains that the current leader's environmental protection consciousness is the main factor affecting the implementation of enterprise environmental behavior. As decision makers and managers of enterprises, leader awareness of environmental protection directly affects whether enterprises are positive in their attitude towards environmental behavior. If enterprises implement forward-looking environmental strategies, environmental values are stronger. The environmental performance of enterprises will also be significantly improved. The path coefficient of enterprise reputation affecting environmental will is 0.760 , which indicates that the pressure brought by public opinion on enterprise environmental behavior can not be underestimated. As an exogenous factor affecting the environmental will of enterprises, corporate reputation promotes enterprises to take more environmental responsibility actively through effective social supervision in order to maintain a good corporate image. The influence coefficient of market profits on the environmental will of enterprises is 0.473 . Optimistic market income expectation can promote the will of pro-environmental behavior of enterprises, but this positive effect does not seem to be significant at present. In the long run, the implementation of environmental behavior can bring positive environmental benefits, but because of the high short-term cost, enterprises that pay attention to shortterm interests are unwilling to take the initiative to implement environmental behavior.

The role of social responsibility in the process of transforming environmental will into environmental behavior is not significant. The reason may be that resource-based enterprises, as important energy enterprises in the country, are highly dependent and destructive to the natural environment, and enterprises will produce a lot of pollution in the process of resource exploitation, thus bringing negative externalities to society [53]. However, compared with other types of enterprises, the green transformation and upgrading of resource-based enterprises face higher costs, so the subjective initiative of enterprises to implement environmental behavior is not strong; secondly, resource-based enterprises are mostly large and medium-sized state-owned enterprises, which hold the lifeblood of local economy, so the local environmental protection departments are more inclined to compromise with them, resulting in the problem of weak supervision or regulation capture, lack of supervision of resourcebased enterprises in the process of fulfilling social responsibility, so the regulatory role is weak [54].

Knowledge sharing plays a regulatory role in the transformation of leader awareness into environmental will. When the enterprise leader actively propagandizes the green knowledge, carries out the related training regularly, it is easier to create the enterprise green production atmosphere, stimulates the employee's green innovation ability, thus causes the leader consciousness to transform into the environment will more easily. And when the level of knowledge sharing is high, this regulation is more intense.

The relevant research conclusions of this paper on the influencing factors of corporate environmental behavior and its mechanism are helpful for enterprises to implement green production behavior and stimulate employees' will to green production behavior. It also reflects the normative effect of effective supervision of government and society on enterprise environmental behavior. Therefore, on the basis of understanding the influence of each intermediary variable and regulating variable, and combining with the heterogeneity of the investigated enterprises, this paper puts forward the following suggestions from three aspects: government, public and enterprise itself:

At the government level, establish and improve the state supervision, local supervision, units responsible for environmental supervision system. Improving the application of environmental laws and regulations and the definition of illegal conditions, serious environmental violations focus on investigation and punishment. On this basis, further strengthen the authenticity and integrity of information disclosure. Strict implementation of total pollutant emission control, emission permits, environmental impact assessment, cleaner production audit, mandatory elimination, deadline control, environmental identification and certification system, relevant departments according to the results of the audit to implement incentive policies for enterprises with better environmental performance, to promote the will of enterprises to take the initiative to implement environmental behavior. To inform the enterprises with poor environmental behavior of fines, closure and rectification of punishment measures to guide enterprises to actively assume environmental responsibility.

At the public level, enhance the level of public participation. The participation of stakeholders such as mainstream media, industry organizations and industry associations will make enterprises face 
multiple pressures to improve environmental behavior. Our government should empower stakeholders through various channels to give them more room for growth. Force the implementation of enterprise environmental behavior and environmental information disclosure [57]. In addition, the government should step up publicity on public awareness of environmental protection, raise awareness of public participation, and fully listen to public opinions on major development planning and construction projects involving public environmental rights and interests through hearings, argumentation meetings or public announcements.

At the enterprise level, enterprises should actively practice environmental behavior and promote the greening of ecological services. At the same time, regular training on environmental awareness, knowledge and skills of employees is carried out, and employees are encouraged to participate in environmental education activities organized by some social organizations and the public to enhance the green culture atmosphere of enterprises. Secondly, enterprises should further increase R \& D investment and actively carry out technological innovation. In the long run, in order to realize the control of pollutant discharge at low cost, advanced energy saving technology and equipment must be used, which requires enterprises to increase innovation and environmental protection investment [58].

\section{Acknowledgements}

This work is supported by a project of the National Social Science Foundation of China (19BGL196), a project funded by Social Science Excellent Youth Project in Jiangsu Province (2019), a project funded by Qinglan Engineering Project in Jiangsu Province (2019), a project funded by the Priority Academic Program Development of Jiangsu Higher Education Institutions (PAPD), a project funded by Jiangsu Province Graduate Research and Practice Innovation Program (KYCX20_2091).

\section{Conflict of Interest}

The authors declare no conflict of interest.

\section{References}

1. HANG Y., WANG Q.W., WANG Y.Z., SU B., ZHOU D.Q. Industrial $\mathrm{SO}_{2}$ emissions treatment in China: A temporalspatial whole process decomposition analysis. Journal of Environmental Management, 243, 419, 2019.

2. STEG L. Promoting household energy conservation. Energy Policy, 36 (12) ,4449, 2008.

3. SARKAR R. Public policy and corporate environmental behavior: a broader view. Corporate Social Responsibility \&Environmental Management, 15 (5), 281, 2008.
4. RONALD G.B.J. When and why do plants comply? Papermills in the1980s. Law \&Policy, 27 (2), 238, 2005.

5. JOSE P.M., L M., FERNANDEZ G.P. GHG emissions in the EU-28. A multilevel club convergence study of the Emission Trading System and Effort Sharing Decision mechanisms. Sustainable Production and Consumption, 27, 998, 2021.

6. ZHANG Q., QU S.Y. Research on dynamic game and optimal strategy of government and enterprise environmental behavior under environmental regulation. Forecast, 32 (04), 35, 2013.

7. LI J., KAGAWA S., LIN C. China's $\mathrm{CO}_{2}$ emission structure for 1957-2017 through transitions in economic and environmental policies. Journal of Cleaner Production, 255 (C) , 120288, 2020.

8. FRONDEL M., HORBACH J., KR. What triggers environmental management and innovation? Empirical evidence for Germany. Ecological Economics, 66 (1), 2007.

9. SUN L.C., WANG Q.W., GE S.L. Urban resident energysaving behavior: a case study under the A2SC framework. Natural Hazards, 91 (2), 515, 2018.

10. ZHA D.L., YANG G.L., WANG W.Z., WANG Q.W., ZHOU D.Q. Appliance energy labels and consumer heterogeneity: A latent class approach based on a discrete choice experiment in China. Energy Economics, 90, 2020.

11. SUGANTHI L. Examining the relationship between corporate social responsibility, performance, employees' pro-environmental behavior at work with green practices as mediator. Journal of Cleaner Production, 232, 2019.

12. ZHOU H.H., WANG S.L. Community environmental pressure, environmental information communication and environmental performance for enterprises. Soft Science, 32 (02), 80, 2018.

13. RAMIREZ M.C., CASTANO L.A.N., DELGADO A. Promoting entrepreneurship through a community learning model - case study: green businesses. Systemic Practice and Action Research, 629, 2019.

14. DENNING K.C., SHASTRI K. Environmental performance and corporate behavior. Journal of Economic and Social Re-search, 2 (1), 13, 2000.

15. HUSSEY D.M., EAGAN P.D. Using structural equation modeling to test environmental performance in small and medium-sized manufacturers: can SEM help SMES. Journal of Cleaner Production, 15 (4), 303, 2007.

16. XUE B., ZHANG Z., LI P.L. Corporate environmental performance, environmental management and firm risk. Business Strategy and the Environment, 29 (3), 1074, 2020.

17. DU Y. Research on the influencing factors of environmental behavior of production enterprises in the context of green growth. Dalian University of Technology, 2015.

18. EARNHART D., LIZAL L. Effects of ownership and financial performance on corporate environmental performance. Journal of Comparative Economics, 34 (1), 2005.

19. CHEN X., CHUN W.D. Environmental performance and economic performance: the type of control and the regulatory role of executive incentives. Contemporary Economic Management, 37 (09), 20, 2015.

20. YANG G.L., ZHA D.L., WANG X.J., CHEN Q. Exploring the nonlinear association between environmental regulation and carbon intensity in China: The mediating effect of green technology. Ecological Indicators, 114, 2020.

21. XIE X.B., WU Y., FENG Z.L., HAO Z.T. A study on green behavior of resource-based enterprises in China. China's population Resources and Environment, 25 (06), 5, 2015. 
22. DOWNING P., KIMBALL J. Enforcing pollution control laws in the United States. Policy Studies Journal, 11, 55, 1982.

23. WALDMAN D.A., SIEGEL D. Defining the socially responsible leader. Leader Quarterly, 19 (1), 117, 2018.

24. WANG F.Z., GUO X.C. The impact of environmental regulation intensity on green technological innovation of resource-based industries - an empirical test based on panel data from 2003-2011. China's population Resources and Environment, 25 (S1), 143, 2019.

25. XIE X.B., SUN L.J., WU Y., ZHOU M. Network relationship, management cognition and enterprise environmental technology innovation behavior - an empirical analysis of resource-based enterprises. Science and Technology Management Research, 39 (23), 142, 2019.

26. ALSAIFI K., ELNAHASS M., SALAMA A. Carbon disclosure and financial performance: UK environmental policy. Business Strategy and the Environment, 29 (2), 711, 2020.

27. LI C.R., YEH C.H. Leveraging the benefits of exploratory learning and exploitative learning in NPD: the role of innovation field orientation. R\&D Management, 47 (3), 484, 2017.

28. PAPA A., DEZI L., GREGORI G.L., MUELLER J., MIGLIETTA N. Improving innovation performance through knowledge acquisition: the moderating role of employee retention and human resource management practices. Journal of Knowledge Management, 24 (3), 589, 2018.

29. AJZEN I. From intentions to actions: a theory of planned behavior. In: Kuhl J, Beckman J, (Eds.), Action control: From cognition to behavior. Heidelberg, Germany: Springer, 11, 1985

30. WANG J.R., ZHANG Y. Environmental regulation, green technological innovation intention and green technological innovation behavior. Scientific Research, 36 (02), 352, 2018.

31. TIAN H.R., ZHANG J., LI J.J. The relationship between pro-environmental attitude and employee green behavior: the role of motivational states and green work climate perceptions. Environmental Science and Pollution Research, 27 (7), 7341, 2020.

32. DUAN W.T., JIANG G.R. A review of the theory of planned behavior. Progress in Psychological Science, (02), 315, 2008.

33. CONCARI A., KOK G., MARTENS P. A Systematic Literature Review of Concepts and Factors Related to ProEnvironmental Consumer Behaviour in Relation to Waste Management Through an Interdisciplinary Approach. Sustainability, 12 (11), 4452, 2020.

34. NORTON T.A., ZACHER H., PARKER S.L., ASHKANASY N.M. Bridging the gap between green behavioral intentions and employee green behavior: The role of green psychological climate. Journal of Organizational Behavior, 38 (7), 996, 2017.

35. XIE X.B., SUN L.J., WU Y., ZHOU M. Network relationship, management cognition and enterprise environmental technology innovation behavior - an empirical analysis of resource-based enterprises. Science and Technology Management Research, 39 (23), 142, 2019.

36. WANG Q.C., CHANG R.D., XU Q., LIU X., JIAN I.Y., MA Y.T., WANG Y.X. The impact of personality traits on household energy conservation behavioral intentions - An empirical study based on theory of planned behavior in Xi'an. Sustainable Energy Technologies and Assessments, 43, 2021
37. ZOU W.J., PEI H.W., WANG J. A study on enterprise environmental behavior based on principal-agent model. China's population Resources and Environment, 24 (S1), $51,2014$.

38. ZHOU M., KANNAN G., XIE X.B., YAN L. How to drive green innovation in China's mining enterprises? Under the perspective of environmental legitimacy and green absorptive capacity. Resources Policy, 72, 2021.

39. XIANG L., HU L.Y. R\&D outsourcing and enterprise green technology innovation: the regulatory role of environmental regulation. Management Modernization, 37 (06), 60, 2017.

40. VILCHEZ V.F., DARNALL N., CORREA J.A.A. Stakeholder influences on the design of firms' environmental practices. Journal of Cleaner Production, 142, 2017.

41. SALEEM M., QADEER F., MAHMOOD F., ARIZAMONTES A., HAN H. Ethical leadership and employee green behavior: A multilevel moderated mediation analysis. Sustainability, 12 (8), 3314, 2020.

42. MO S.Y., ZHANG C.J. Empirical evidence of environmental values, environmental behavior and environmental performance from listed companies in China's heavy-polluting industry. Monthly Journal of Accounting, 36, 13, 2016.

43. HOTTE K. How to accelerate green technology diffusion? Directed technological change in the presence of coevolving absorptive capacity. Energy Economics, 85 (C), 2020.

44. CAO Y., XIANG Y. Corporate knowledge governance, knowledge sharing and employee innovation behavior the mediating effect of social capital and the regulating effect of absorptive capacity. Scientific Research, 32 (01), 92, 2014.

45. HE J., WANG H.C. Innovative knowledge assets and economic performance: the asymmetric roles of incentives and monitoring. Academy of Management Journal, 52 (5), 919, 2009

46. TAUSCZIK Y., HUANG X.Y. Knowledge generation and sharing in online communities: current trends and future directions. Current Opinion in Psychology, 36, 60, 2020.

47. FREEMAN R.E. Strategic management: a stakeholder approach. Cambridge University Press, 1984.

48. XU S.K., YANG R.D. An inductive analysis of the conceptual category of corporate social responsibility. China Industrial Economy, 05, 71, 2007.

49. YIN L.L. Stakeholder stress, corporate environmental behavior and environmental performance. Zhejiang University of Technology, 2018.

50. CHU H.W., EI-MANSRLY D., TSENG M.L.,RAMAYAH T. Sustaining customer engagement behavior through corporate social responsibility: The roles of environmental concern and green trust. Ecology, Environment \& Conservation, 262, 2020.

51. QU L.J. A study on the environmental values and impacts of enterprises. North University of Technology, 2019.

52. WANG S.J., ZHOU H.Y. The empirical test on the influence of environmental values on ecological consumption behavior - based on intermediary variables. Soft Science, 33 (10), 50, 2019.

53. WEN Z.L., HOU J.T., HERBERT M. Analysis of structural equation model: of fitting index and chi-square criterion. Psychology Report, 02, 186, 2004.

54. YANG L., YU A.P. The influence of entrepreneur's cognition on the forward-looking change of enterprise's 
strategy: the intermediation effect of knowledge creation process. Nankai Management Review, 19 (01), 120, 2016.

55. LI H.J. Study on the impact of personnel incentive system embedded in cultural differences on the performance of international engineering project management. Shandong University, 2019.

56. ALIKEN L.S., WEST S.G. Multiple regression: testing and interpreting interactions. London: Sage, 1991.

57. AFSAR B., AL-GHAZALI B.M., REHMAN Z.U., The moderating effects of employee corporate social responsibility motive attributions (substantive and symbolic) between corporate social responsibility perceptions and voluntary pro-environmental behavior. Corporate Social Responsibility and Environmental Management, 27 (2), 769, 2020.

58. CHANG T.W. Corporate sustainable development strategy: effect of green shared vision on organization members' behavior. International Journal of Environmental Research and Public Health, 17 (7), 2020. 
